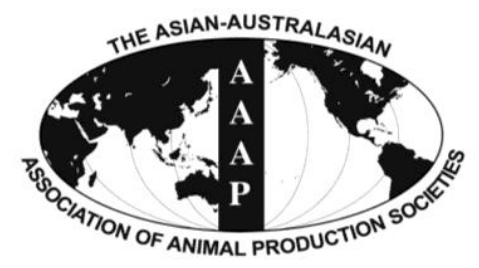

Asian Australas. J. Anim. Sci.

Vol. 26, No. 5 : 700-704 May 2013

http://dx.doi.org/10.5713/ajas.2012.12561

www.ajas.info

pISSN $1011-2367$ elSSN 1976-5517

\title{
Growth Performance, Plasma Fatty Acids, Villous Height and Crypt Depth of Preweaning Piglets Fed with Medium Chain Triacylglycerol
}

\author{
Loh Teck Chwen ${ }^{1,2, *}$, Hooi Ling Foo ${ }^{3,4}$, Nguyen Tien Thanh ${ }^{1}$ and D. W. Choe ${ }^{1}$ \\ ${ }^{1}$ Department of Animal Science, Faculty of Agriculture, University Putra Malaysia, \\ 43400 UPM Serdang, Selangor, Malaysia
}

\begin{abstract}
A study was conducted to investigate the effects of feeding medium chain triacylglycerol (MCT) on growth performance, plasma fatty acids, villus height and crypt depth in preweaning piglets. A total of 150 new born piglets were randomly assigned into one of three treatments: i) Control (no MCT); ii) MCT with milk (MCT+milk); iii) MCT without milk (MCT+fasting). Body weight, plasma fatty acid profiles, villus height and crypt depth were measured. Final BW for the Control and MCT+fasting was lower $(p<0.05)$ than MCT+milk. The piglets fed with MCT regardless of milk provision or fasting had greater medium chain fatty acids (MCFA) than the Control. In contrast, the Control had greater long chain fatty acid (LCFA) and unsaturated fatty acid (USFA) than the MCT piglets. The piglets fed with MCT regardless of milk provision or fasting had higher villus height for the duodenum and jejunum after $6 \mathrm{~h}$ of feeding. Similar observations were found in piglets fed with MCT after 6 and 8 days of treatment. This study showed that feeding MCT to the piglets before weaning improved growth performance, with a greater concentration of MCT in blood plasma as energy source and a greater height of villus in duodenum, jejunum and ileum. (Key Words: Medium Chain Triacylglycerol, Villus, Fatty Acids, Piglets)
\end{abstract}

\section{INTRODUCTION}

Preweaning mortality in piglets is still a major problem in the swine industry. The mortality rate can range from 10 to $14 \%$ and normally occurs during the first seven days post-partum. One of the major causes of this mortality is a deficit of neonatal energy reserves (Pettigrew, 1981) due to low body fat content. The piglets have low energy reserves in the form of fat but high reserves in form of glycogen. However, the stores of glycogen fall rapidly in the liver in the first $18 \mathrm{~h}$ and in skeletal muscle in the first $48 \mathrm{~h}$. Thus, milk produced from sow plays a pivotal role in determining

\footnotetext{
* Corresponding Author: Loh Teck Chwen. Tel: +603-89474814, Fax: +603-89381024, E-mail: tcloh@ @utra.upm.edu.my

${ }^{2}$ Institute Tropical Agriculture, University Putra Malaysia, 43400 UPM Serdang, Selangor, Malaysia.

${ }^{3}$ Department of Bioprocess Technology, Faculty of Biotechnology and Biomolecular Sciences, University Putra Malaysia, 43400 UPM Serdang, Selangor, Malaysia.

${ }^{4}$ Institute of Bioscience University Putra Malaysia, 43400 UPM Serdang, Selangor, Malaysia.

Submitted Oct. 9, 2012; Accepted Dec. 15, 2012; Revised Jan. 19, 2013
}

the survivability of preweaning piglets. Considerable emphasis has been placed on influencing neonatal energy stores by maternal manipulation. Supplementation of fat in the dam's diet during late pregnancy could improve the preweaning survival of the offspring by improving their milk fat content (Pettigrew et al., 1986; Loh et al., 2002). The use of fat in pig diet affects the quantity and quality of the milk produced by the sow which leads to a better well being of the newborn piglets. It has been reported that raising dietary fat to $8.0 \%$ increased the fat and improved the performance of progeny by increasing the output of fat and energy into sow milk (Lauridsen and Danielsen, 2004). Titlton et al. (1999) claimed that the sows fed with $10 \%$ tallow had a small increase in sow energy intake and milk fat content with little effect on litter growth rate as compared with the sow fed with a conventional corn-soya bean meal diet. These results indicate that the effects of fat inclusion in the diet of sows on their energy reserve are not consistent. It is, therefore, suggested to offer the fat to preweaning piglets as a mean of improving survival. The common fat used in preweaning piglets is medium-chain triacylglycerol (MCT) (Wieland et al., 1993). MCT is a 
class of fatty acids containing six to twelve carbons in their chemical structure. MCT are passively diffused and rapidly absorbed, and transported to the liver. Rapid transportation and oxidation occurring in MCT is similar to carbohydrate than to other fats. Additionally, MCT have less of a tendency to store as body fat and do not require bile for emulsification and digestion. Most of the MCT are metabolized by the liver and provide energy, some ketone bodies will also be produced and eliminated in the urine or used as alternative fuel source by the muscles and the brain when the body is in a starvation state. Administration MCT in late gestating sow to improve survival of piglets, particularly small ones have been reported (Newcomb et al., 1981; Azain, 1993). Likewise, oral administration of MCT to piglets in a litter shortly after birth is rationally important to provide a quick energy restoration. However, the information on the effects of oral administration of MCT in preweaning piglets on intestinal structure and growth performance are still very limited. Thus, this experiment was conducted to study the effects of MCT on villus height and crypt depth of small intestine, plasma lipids, growth performance of piglets from birth until 8 days of age.

\section{MATERIAL AND METHODS}

\section{Experimental animals}

A total of 150 new born Landrace $\times$ Large White $\times$ Duron piglets obtained from 15 postpartum (Landrace $\times$ Large White) sows with 4 to 5 parity were used in this study. This experiment was conducted in a commercial pig farm in Tanjung Sepat, Selangor, Malaysia. The piglets were randomly assigned into three treatment groups of 50 animals each with 5 replicates per treatment. Each experimental unit consisted of 10 piglets. The piglets were allocated to the following treatments: i) Control (no MCT), ii) MCT with milk (MCT+milk) iii) MCT without milk (MCT+fasting). The MCT offered to the piglets was five $\mathrm{mL}$ per piglet. The fatty acid composition in MCT are shown in Table 1. The MCT was obtained from Sunzen Corp., Malaysia (Mamimune ${ }^{\mathrm{TM}}$ ). A piglet from each treatment was sacrificed in order to collect their blood as well as small intestine before commencement of the experiment. The experiment was conducted for 8 days. MCT was offered to the piglets on $d 1,3$ and 5 (d 1 indicates the day of birth). Six ml of blood samples were collected from the jugular vein of 3 piglets from each treatment at h 0,2, 4 and 6 on the day of MCT was offered (d 1).

\section{Preparation of plasma samples}

The blood samples were collected for plasma fatty acid profile analyses. The method determination of fatty acids was modified from Oliveira et al. (2009). The plasma was
Table 1. The fatty acid composition of MCT (as mean \% of total fatty acids)

\begin{tabular}{lr}
\hline Fatty acids & $\%$ \\
\hline C6:0 (Caproic) & 0.06 \\
C8:0 (Caprylic) & 58.05 \\
C10:0 (Capric) & 37.13 \\
C11:0 (Undecanoic) & 0.42 \\
C12:0 (Lauric) & 0.09 \\
C14:0 (Myristic) & 0.01 \\
C15:1 (cis-10-Pentadecenoic) & 0.16 \\
C17:0 (Heptadecanoic) & 0.02 \\
C17:1 (cis-10-Heptadecenoic) & 0.16 \\
C18:0 (Stearic) & 0.15 \\
C18:1n9t (Elaidic) & 1.74 \\
C18:2n6c (Linoleic) & 0.10 \\
C18:2n6t (Linolelaidic) & 0.43 \\
C18:3n6 (Linolenic) & 0.55 \\
C18:3n3 (a-Linolenic) & 0.09 \\
C20:0 (Arachidic) & 0.16 \\
C20:1n9 (cis-11-Eicosenoic) & 0.10 \\
C20:2 (cis-11,14-Eicosadienoic) & 0.36 \\
C20:3n6 (cis-8,11,14-Eicosatrienoic) & 0.0 .09 \\
C20:3n3 (cis-11,14,17-Eicosatrienoic) & 926.48 \\
SCFA ${ }^{1}$ & \\
MCFA & \\
LCFA $^{3}$ & 0.13 \\
USFA & 4 \\
SSFA & \\
Overall (mg/ml) & 0.07 \\
\hline SCFA Shot-cin & 0.06 \\
&
\end{tabular}

${ }^{1}$ SCFA $=$ Short-chain fatty acids $(<\mathrm{C} 8)$.

${ }^{2} \mathrm{MCFA}=$ Medium-chain fatty acids (C8 to $\left.\mathrm{C} 12\right)$.

${ }^{3}$ LCFA $=$ Long-chain fatty acids $(\mathrm{C} 13$ to $\mathrm{C} 20)$.

${ }^{4} \mathrm{USFA}=$ Unsaturated fatty acids. ${ }^{5} \mathrm{SSFA}=$ Saturated fatty acids.

mixed with chloroform-methanol and flushed by nitrogen before filtered through Whatman paper to collect liquid solution. The sample solution was continually extracted by several procedures to harvest fatty acid methyl esters and kept at $4{ }^{\circ} \mathrm{C}$ until analysis by gas chromatography.

\section{Collection of small intestine}

At the end of experiment, all the piglets were weighed and 3 piglets from each treatment (only the groups $\mathrm{i}$ and ii) were sacrificed in order to collect their blood samples and small intestine. The small intestine was collected for the 10 $\mathrm{cm}$ of proximal duodenum and jejunum, respectively for histological examination. The samples from the middle of duodenum, jejunum and ileum of small intestine of each segment was sectioned 6 to $8 \mathrm{~cm}$, flushed and kept in neutral buffered formalin solution until further morphometric analysis. The samples were then cut into two parts from each segment for cross and length section of intestine surface. Each segment was fixed in $10 \%$ formalin. Intestinal samples were excised and dehydrated for $16 \mathrm{~h}$ in 
tissue processing machine (Leica ASP 3000, Japan) then embedded in paraffin wax (Leica EG 1160, Japan). Each section was cut $4 \mu \mathrm{m}$ thicknesses (Leica RM 2155, Japan) and fixed on to the glass slides, heated at $57^{\circ} \mathrm{C}$ until samples were dried. The samples were stained with haematoxylin and eosin, mounted with cover slips. The villus height was measured as the distance between the crypt mouth and the tip of villi. The crypt depth was measured as the distance between the basement membrane and the mouth of crypt as using microscopes and read by PC Life Science Olympus software (Olympus Soft Imaging Solutions). This procedure was based on the method described by Thu et al. (2011).

Results were expressed as mean \pm standard error of mean (SEM). One way ANOVA was used to analyse the data. All statistics were carried out using the SAS software (1998).

\section{RESULTS}

Table 1 shows the fatty acid composition of MCT (as mean $\%$ of total fatty acids). The fatty acid is categorized based on the number of carbon atoms: short chain fatty acid with $<8$ carbons, medium chain fatty acids with $\mathrm{C} 8$ to 12 and long chain fatty acid $\mathrm{C} 13$ to $\mathrm{C} 20$. The MCT contained $0.06 \%, 95.69 \%$ and $4.23 \%$ for SCFA, MCFA and LCFA, respectively.

Body weight and weight gain of the piglets fed with MCT is shown in Table 2. The piglets in MCT+milk and $\mathrm{MCT}+$ fasting were not significantly different $(\mathrm{p}>0.05)$ compared to the control piglets for the initial stage of experiment. Body weight of piglets with MCT+milk was significantly higher than the control and MCT+fasting on $\mathrm{d}$ 6 and 8. The control and MCT+fasting had no significant difference $(p>0.05)$ in body weight on $\mathrm{d} 6$ and 8 . The body weight gain for the MCT+milk piglets was the highest $(\mathrm{p}<0.05)$ among the treatments. Interestingly, the body weight gain for the MCT+fasting had slightly higher weight gain than the control piglets, although the results were not significantly different $(p>0.05)$. These results show that

Table 2. Body weight and weight gain of piglets at d 1, 6 and 8 after farrowing

\begin{tabular}{lccc}
\hline $\begin{array}{l}\text { Body weight } \\
\text { and weight } \\
\text { gain }(\mathrm{kg})\end{array}$ & Control & MCT+milk & MCT+fasting \\
\cline { 2 - 4 } & $1.72 \pm 0.04$ & $1.63 \pm 0.05$ & $1.51 \pm 0.20$ \\
BW1 & $2.42 \pm 0.05^{\mathrm{a}}$ & $2.59 \pm 0.06^{\mathrm{b}}$ & $2.27 \pm 0.06^{\mathrm{a}}$ \\
BW6 & $2.71 \pm 0.06^{\mathrm{a}}$ & $2.96 \pm 0.07^{\mathrm{b}}$ & $2.63 \pm 0.07^{\mathrm{a}}$ \\
BW8 & $0.69 \pm 0.04^{\mathrm{a}}$ & $0.97 \pm 0.04^{\mathrm{b}}$ & $0.75 \pm 0.08^{\mathrm{a}}$ \\
WG1-6 & $0.99 \pm 0.05^{\mathrm{a}}$ & $1.33 \pm 0.05^{\mathrm{b}}$ & $1.11 \pm 0.12^{\mathrm{ab}}$ \\
\hline WG1-8 &
\end{tabular}

$\mathrm{n}=150$. The results are presented as mean \pm standard error of mean (SEM).

${ }^{a-b}$ Values within each row with different superscript were significantly differ $(\mathrm{p}<0.05)$.
MCT may help to gain weight in the milk or non-milk situation. However, the benefits of MCT are enhanced when the diet also includes milk.

Table 3 shows the fatty acid profile in plasma of piglets in different treatment groups at $0,2,4,6 \mathrm{~h}$ after application of MCT. The MCFA increased $(\mathrm{p}<0.05)$ tremendously for those treated with MCT piglets as compared with control piglets. The results of MCT+fasting show that the absorption of MCFA was greater when no milk was provided to the piglets, this may alleviate the piglets from starvation in case of insufficient milk production from the

Table 3. Fatty acid profile in plasma of piglets in different treatment groups at different hours after application of MCT

\begin{tabular}{|c|c|c|c|}
\hline \multirow{2}{*}{ Parameters } & \multicolumn{3}{|c|}{ Treatments } \\
\hline & Control & MCT+milk & MCT+Fasting \\
\hline & & $0 \mathrm{~h}$ & \\
\hline $\operatorname{SCFA}^{1}(\%)$ & $1.80 \pm 0.05$ & $2.01 \pm 0.48$ & $1.45 \pm 0.85$ \\
\hline $\operatorname{MCFA}^{2}(\%)$ & $1.99 \pm 0.07^{\mathrm{a}}$ & $2.30 \pm 0.09^{\mathrm{ab}}$ & $31.27 \pm 6.67^{b}$ \\
\hline $\operatorname{LCFA}^{3}(\%)$ & $97.41 \pm 0.67^{\mathrm{b}}$ & $96.70 \pm 0.92^{\mathrm{b}}$ & $67.28 \pm 6.95^{\mathrm{a}}$ \\
\hline $\operatorname{USFA}^{4}(\%)$ & $55.93 \pm 0.19^{\mathrm{b}}$ & $39.07 \pm 7.47^{\mathrm{b}}$ & $19.48 \pm 4.28^{\mathrm{a}}$ \\
\hline $\operatorname{SSFA}^{5}(\%)$ & $44.07 \pm 0.19^{\mathrm{a}}$ & $60.93 \pm 7.47^{\mathrm{a}}$ & $80.52 \pm 4.28^{\mathrm{b}}$ \\
\hline & $143.50 \pm 11.20^{\mathrm{ab}}$ & $121.48 \pm 4.60^{\mathrm{a}}$ & $165.10 \pm 11.50^{\mathrm{b}}$ \\
\hline $\operatorname{SCFA}^{1}(\%)$ & $1.05 \pm 0.25$ & $1.73 \pm 0.38$ & $1.91 \pm 0.76$ \\
\hline $\operatorname{MCFA}^{2}(\%)$ & $3.58 \pm 0.28^{\mathrm{a}}$ & $28.06 \pm 4.88^{\mathrm{b}}$ & $55.86 \pm 4.14^{\mathrm{c}}$ \\
\hline $\operatorname{LCFA}^{3}(\%)$ & $95.90 \pm 0.81^{\mathrm{a}}$ & $70.21 \pm 4.54^{\mathrm{b}}$ & $43.50 \pm 4.16^{\mathrm{c}}$ \\
\hline $\mathrm{USFA}^{4}(\%)$ & $44.00 \pm 11.00^{\mathrm{a}}$ & $30.59 \pm 1.96^{\mathrm{ab}}$ & $19.56 \pm 4.99^{\mathrm{b}}$ \\
\hline $\operatorname{SSFA}^{5}(\%)$ & $56.00 \pm 11.00^{\mathrm{a}}$ & $69.40 \pm 1.96^{\mathrm{ab}}$ & $80.44 \pm 4.99^{\mathrm{b}}$ \\
\hline Overall & $196.4 \pm 16.70$ & $180.40 \pm 31.30$ & $220.00 \pm 38.40$ \\
\hline $\operatorname{SCFA}^{1}(\%)$ & $2.04 \pm 0.03$ & $1.80 \pm 0.45$ & $3.30 \pm 2.72$ \\
\hline $\operatorname{MCFA}^{2}(\%)$ & $3.06 \pm 0.82^{\mathrm{a}}$ & $30.20 \pm 2.67^{\mathrm{b}}$ & $41.51 \pm 5.71^{\mathrm{b}}$ \\
\hline $\operatorname{LCFA}^{3}(\%)$ & $95.59 \pm 1.49^{\mathrm{a}}$ & $67.99 \pm 2.44^{\mathrm{b}}$ & $56.28 \pm 7.31^{\mathrm{b}}$ \\
\hline $\mathrm{USFA}^{4}(\%)$ & $53.42 \pm 0.95^{\mathrm{a}}$ & $36.28 \pm 1.69^{b}$ & $22.01 \pm 6.02^{\mathrm{c}}$ \\
\hline $\operatorname{SSFA}^{5}(\%)$ & $46.58 \pm 0.95^{\mathrm{a}}$ & $63.72 \pm 1.69^{\mathrm{b}}$ & $77.99 \pm 6.02^{\mathrm{c}}$ \\
\hline $\begin{array}{l}\text { Overall } \\
(\mathrm{mg} / 100 \mathrm{ml})\end{array}$ & $148.30 \pm 16.90$ & $209.60 \pm 19.40$ & $183.50 \pm 35.10$ \\
\hline
\end{tabular}

\begin{tabular}{lccc} 
& - & ----------------- \\
$\operatorname{SCFA}^{1}(\%)$ & $1.25 \pm 0.13$ & $1.57 \pm 0.36$ & $0.86 \pm 0.25$ \\
$\operatorname{MCFA}^{2}(\%)$ & $1.15 \pm 0.25^{\mathrm{a}}$ & $32.01 \pm 6.45^{\mathrm{b}}$ & $44.12 \pm 1.41^{\mathrm{b}}$ \\
$\mathrm{LCFA}^{3}(\%)$ & $98.92 \pm 0.13^{\mathrm{b}}$ & $66.43 \pm 6.44^{\mathrm{a}}$ & $55.59 \pm 1.17^{\mathrm{a}}$ \\
$\mathrm{USFA}^{4}(\%)$ & $38.30 \pm 18.30$ & $30.48 \pm 2.80$ & $21.60 \pm 0.72$ \\
$\operatorname{SSFA}^{5}(\%)$ & $61.70 \pm 18.30$ & $69.52 \pm 2.80$ & $78.40 \pm 0.72$ \\
Overall & $215.30 \pm 52.80$ & $214.70 \pm 17.40$ & $168.30 \pm 12.30$ \\
$(\mathrm{mg} / 100 \mathrm{ml})$ & & & \\
\hline
\end{tabular}

${ }^{1}$ SCFA: Short-chain fatty acids $(<\mathrm{C} 8) ;{ }^{2}$ MCFA: Medium-chain fatty acids (C8 to C12); ${ }^{3}$ LCFA: Long-chain fatty acids (C13 to C20); ${ }^{4}$ USFA: Unsaturated fatty acids; ${ }^{5}$ SSFA: Saturated fatty acids.

$\mathrm{n}=9$. The results are presented as mean \pm standard error of mean (SEM).

a-b Values within each row with different superscript were significantly differ $(\mathrm{p}<0.05)$. 
sows. The greater amount of MCFA in the plasma of MCT may contribute to a greater amount of overall FA in the plasma. The results of MCFA and overall fatty acids of piglets fed with MCT were significantly greater $(p<0.05)$ than the control piglets. In contrast, LCFA and USFA for the control piglets were significantly greater $(p<0.05)$ than the MCT piglets. These results indicate that the MCT is absorbed easily by the piglets as a greater amount was found in the plasma in the present study. The MCFA is a useful source of energy for the piglets.

Table 4 shows the villus height and crypt depth of piglets $6 \mathrm{~h}$ after offering MCT. The piglets fed with MCT had greater $(p<0.05)$ villus height for the duodenum and jejunum. The duodenal crypt for control was significantly lower $(\mathrm{p}<0.05)$ than the MCT. The jejunal and ileal crypts were statistically significant $(\mathrm{p}>0.05)$.

Villus height and crypt depth of piglets at 6 and 8 days old, respectively from different treatment groups are shown in Table 4. The MCT piglets had greater $(\mathrm{p}<0.05)$ duodenal and jejunal villus height as compared with control piglets at 6 and 8 days of age. The ileal villus height at 6 days of age was not significantly different $(p>0.05)$ between control and MCT. In contrast, the ileal villus height at 8 days for MCT was significantly higher $(p<0.05)$ than the control piglets.

Table 4. Villus height and crypt depth of piglets in different treatment groups at different times after offering with MCT

\begin{tabular}{|c|c|c|}
\hline $\begin{array}{l}\text { Villus height } \\
\text { and crypt depth }(\mu \mathrm{m})\end{array}$ & Control & MCT \\
\hline & \multicolumn{2}{|c|}{--------------------- 6 h ---------------- } \\
\hline Duodenal villus & $1018.70 \pm 36.10^{\mathrm{b}}$ & $1498.20 \pm 36.40^{\mathrm{a}}$ \\
\hline Jejunal villus & $1244.40 \pm 56.60^{\mathrm{b}}$ & $1696.40 \pm 14.40^{\mathrm{a}}$ \\
\hline Ileal villus & $1167.00 \pm 27.50^{\mathrm{b}}$ & $977.30 \pm 30.50^{\mathrm{a}}$ \\
\hline Duodenal crypt & $86.00 \pm 5.62^{\mathrm{b}}$ & $113.00 \pm 7.31^{\mathrm{a}}$ \\
\hline Jejunal crypt & $75.00 \pm 6.54^{\mathrm{a}}$ & $65.00 \pm 3.42^{\mathrm{a}}$ \\
\hline \multirow[t]{2}{*}{ Ileal crypt } & $151.00 \pm 8.23^{\mathrm{a}}$ & $170.00 \pm 9.19^{\mathrm{a}}$ \\
\hline & \multicolumn{2}{|c|}{ 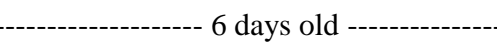 } \\
\hline Duodenal villus & $801.00 \pm 42.70^{\mathrm{a}}$ & $1313.50 \pm 26.00^{\mathrm{b}}$ \\
\hline Jejunal villus & $1125.50 \pm 58.40^{\mathrm{a}}$ & $1584.50 \pm 33.50^{\mathrm{b}}$ \\
\hline Ileal villus & $863.60 \pm 29.70^{\mathrm{a}}$ & $856.90 \pm 57.60^{\mathrm{a}}$ \\
\hline Duodenal crypt & $161.50 \pm 7.99^{\mathrm{a}}$ & $128.50 \pm 3.86^{\mathrm{b}}$ \\
\hline Jejunal crypt & $80.00 \pm 4.81^{\mathrm{a}}$ & $77.50 \pm 4.03^{\mathrm{a}}$ \\
\hline \multirow[t]{2}{*}{ Ileal crypt } & $141.00 \pm 8.52^{\mathrm{a}}$ & $213.00 \pm 13.00^{\mathrm{b}}$ \\
\hline & \multicolumn{2}{|c|}{ 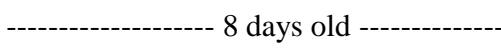 } \\
\hline Duodenal villus & $1070.00 \pm 42.10^{\mathrm{a}}$ & $1225.50 \pm 36.60^{b}$ \\
\hline Jejunal villus & $985.50 \pm 35.00^{\mathrm{a}}$ & $1478.60 \pm 36.90^{\mathrm{b}}$ \\
\hline Ileal villus & $704.50 \pm 26.20^{\mathrm{a}}$ & $1034.50 \pm 48.80^{\mathrm{b}}$ \\
\hline Duodenal crypt & $231.00 \pm 18.60^{\mathrm{a}}$ & $124.00 \pm 4.55^{\mathrm{b}}$ \\
\hline Jejunal crypt & $113.50 \pm 5.09^{\mathrm{a}}$ & $92.50 \pm 4.86^{\mathrm{b}}$ \\
\hline Ileal crypt & $161.50 \pm 9.44^{\mathrm{a}}$ & $166.00 \pm 748^{\mathrm{a}}$ \\
\hline
\end{tabular}

$\mathrm{n}=18$. The results are presented as mean \pm standard error of mean (SEM).

${ }^{\mathrm{a}-\mathrm{b}}$ Values within each row with different superscript were significantly differ $(\mathrm{p}<0.05)$
The duodenal crypt depth for MCT was significantly lower $(p<0.05)$ than the control at 6 and 8 days of ages. At 6 days of age, the jejunal crypt was not significantly different ( $>0.05$ ) among the treatment groups. In contrast, ileal crypt for MCT was significantly greater $(p<0.05)$ than the control. At 8 days of age, the MCT had a lower $(\mathrm{p}<0.05)$ jejunal crypt as compared with the control piglets. However, no significant $(p>0.05)$ difference was found for the ileal crypt among the treatment groups.

\section{DISCUSSION}

Highest body weight gain was observed in piglets treated with MCT+milk compared with the other 2 treatment groups on d 6 and 8 . However, there were no significant differences in body weight gain between the control group and MCT+fasting. This is a clear indication that MCT is able to exert positive effect with or without the presence of maternal milk in the piglets' diet. Pigs are normally born with a relatively low lipid energy reserve. They have a larger amount of reserve in the form of glycogen, but much of this glycogen is depleted during the first few days after birth. As the endogenous energy storage is limited at birth, sufficient quantity and quality of milk intake during the first few days of birth is crucial to ensure piglets survival but usually, the maternal milk supply is inadequate. Therefore, supplementation of MCT to preweaning pigs could serve as an alternative source of energy which is important for normal body metabolism processes such as building tissues and excreting waste materials (Jean and Chiang, 1999). Hence, the body reserves could be spared resulting in better body weight gain. In addition, MCT is able to improve calcium and amino acids uptake to increase intracellular protein synthesis (Galluser et al., 1993) and promoting epithelial cell regeneration. The combination of these effects would contribute to better absorption ability of the intestinal tract and yields a better growth performance.

The MCFA of piglets fed with MCT were significantly higher $(\mathrm{p}<0.05)$ than the control pigs. Bach and Babayan (1982) indicated that MCT had smaller molecular weight and higher water solubility. MCTs could passively diffuse from the intestinal capillaries as free fatty acids and travel via the portal venous system directly into the hepatic system without requiring modification unlike long chain fatty acids. Whereas, long chain fatty acids are transported via the lymph into the systemic circulation before going into the hepatic system in the form of lipoproteins which are insoluble particles. Thus, the amount of long chain fatty acids may reduce as some portion may be retained in the systemic circulation or extra-hepatic tissues. Therefore, the absorption and availability of MCT in the systemic 
circulation is much higher and a greater amount can be found in the plasma. In this experiment, higher level of overall FA in the plasma of piglets fed with MCT was probably contributed to by the increased amount of MCFA in the systemic circulation.

In general, the piglets fed with MCT had greater villus height in the duodenum, jejunum and ileum compared with the control groups. Villi are important structures in the small intestine which is involved mainly in nutrient absorption (Fuller, 2004). The increase of villi height would directly affect the nutrient absorption capability in the intestine as it would increase the absorptive and surface area. Czernichow et al. (1996) cited that supplementation of MCT is capable of stimulating mucosal growth and enhanced epithelial cell regeneration resulting in a better developed intestinal tract. Hence, MCT may improve the absorption and utilisation of nutrients to enhance the growth performance. The findings in this experiment coincides with research done by Mekbungwan and Yamauchi (2004) who found a positive association between an increased in villi height and an increased in piglets body weight.

Intestinal crypts are invaginations of the epithelium around the villi, and are lined by epithelial cells which secrete enzymes. The base of the crypts is constantly dividing to maintain the structure of the villi. Therefore, an increase in crypt depth would produce more developed villi. In general, supplementation of MCT is able to improve the development of the gut as a whole. However, this experiment showed a significant increase of crypt depth only in the ileum of piglets treated with MCT compared to the control group.

\section{CONCLUSIONS}

The piglets treated with MCT had a better growth performance than the control. MCT may help to improve the weight gain of piglets in the situations of milk or nonmilk. The benefits of MCT in improving the weight gain are more pronounced when fed in conjunction with milk from the mother. These positive effects could be explained by the greater concentrations of MCFA and overall FA in the plasma of MCT. This indicates the absorption of MCFA in MCT is better than the control. These were further shown in the results of MCT+fasting. The MCT piglets had a greater villus height compared with the control piglets which would increase surface area for absorption of nutrients as seen in the MCFA and overall FA in the plasma.

\section{REFERENCES}

Azain, M. J. 1993. Effects of adding medium chain triglycerides to sow diets during late gestation and early lactation on litter performance. J. Anim. Sci. 71:3011-3019.

Jean, K. B. and S. H. Chiang. 1999. Increased survival of neonatal pigs by supplementing medium chained triglycerides in late gestating sow diets. Anim. Feed Sci. Technol. 76:241-250.

Bach, A. C. and V. K. Babayan. 1982. Medium chain triglycerides: an update. Am. J. Clin. Nutr. 36:950-962.

Czernichow, B., M. Galluser, S. Q. Cui, F. Gosse and F. Raul. 1996. Comparison of enteral or parenteral administration of medium chained triglycerides on intestinal mucosa in adult rats. Nutr. Res. 16:797-804.

Fuller, M. F. 2004. The Encyclopedia of Farm Animal Nutrition. CAB International Publishing, UK.

Galluser, M., B. Czernichow, H. Dreyfus, F. Goose, B. Guerold, J. Kachelhoffer, M. Doffoel and F. Raul. 1993. Comparison of different lipid substrates on intestinal adaptation in the rat. Gut. 34:1069-1074.

Luridsen, C. and V. Danielsen. 2004. Lactational dietary fat levels and sources influence milk composition and performance of sows and their progeny. Livest. Prod. Sci. 91:95-105.

Loh, T. C., H. L. Foo, Z. Abdul Wahab and B. K. Tan. 2002. Effects of feeding fat during pregnancy and lactation on growth performance, milk compositions and very low density lipoprotein compositions in rats. Malaysian J. Nutr. 8:125-135.

Mekbungwan, A. and K. Yamauchi. 2004. Growth performance and histological intestinal alterations in piglets fed dietary raw and heated pigeon pea seed meal. Histol. Histopathol. 19:381389

Newcomb, M. D., D. L. Harmon, J. L. Nelssen, A. J. Thulin and G. L. Allee. 1991. Effect of energy source fed to sows during late gestation on neonatal blood metabolite homeostasis, energy stores and composition. J. Anim. Sci. 69:230-236.

Oliveira, A. N., R. M. Prado, C. A. Fugita, P. P. Rotta and N. E. de Souza. 2009. Chemical composition, fatty acid profile and CLA levels in the Longissimus muscle of Caracu and Caracu vs Charolais cattle. Semina: Ciênc. Agric. 30:727-236.

Pettigrew, J. E. Jr. 1981. Supplemental dietary fat for peripartal sows: A review. J. Anim. Sci. 53:107-117.

Pettigrew, J. E., S. G. Cornelius, R. L. Moser, T. R. Heeg, H. E. Hanke, K. P. Miller and C. D. Hagen. 1986. Effects of oral doses of corn oil and other factors on preweaning survival and growth of piglets. J. Anim. Sci. 62:601-612.

SAS Institute. 1998. SAS User's Guide. Statistics. SAS Institute, Inc., Cary, NC, USA.

Thu, T. V., T. C. Loh, H. L. Foo, Y. Halimatun and M. H. Bejo. 2011. Effects of liquid metabolite combinations produced by Lactobacillus plantarum on growth performance, faeces characteristics, intestinal morphology and diarrhoea incidence in postweaning piglets. Trop. Anim. Health Prod. 43:69-75.

Tilton, S. L., P. S. Miller, A. J. Lewis, D. E. Reese and P. M. Ermer. 1999. Addition of fat to the diets of lactating sows: I. Effects on milk production and composition and carcass composition of the litter at weaning. J. Anim. Sci. 77:2491-2500.

Wieland, T. M., X. Lin and J. Odle. 1993. Emulsification and fatty-acid chain length affect the utilization of medium-chain triglycerides by neonatal pigs. J. Anim. Sci. 71:1869-1874. 